\title{
Reclassification of Clostridium hydroxybenzoicum as Sedimentibacter hydroxybenzoicus gen. nov., comb. nov., and description of Sedimentibacter saalensis sp. nov.
}

${ }^{1}$ Institut für Mikrobiologie, Martin-Luther-Universität Halle, Kurt-Mothes-Straße 3, 06099 Halle, Germany

2 Department of Microbiology, University of Georgia, Athens, GA 30602, USA

${ }^{3}$ Umweltforschungszentrum Leipzig-Halle $\mathrm{GmbH}_{\text {, }}$ Permoserstraße 15, 04318 Leipzig, Germany

${ }^{4}$ DSMZ - Deutsche Sammlung von Mikroorganismen und Zellkulturen, Mascheroder Weg 1b, 38124 Braunschweig, Germany

\author{
Antje Breitenstein, ${ }^{1}$ Juergen Wiegel, ${ }^{2}$ Claus Haertig, ${ }^{3}$ Norbert Weiss, ${ }^{4}$ \\ Jan R. Andreesen ${ }^{1}$ and Ute Lechner ${ }^{1}$
} Author for correspondence: Ute Lechner. Tel: +49345 5526353. Fax: + 493455527010.
e-mail: u.lechner@mikrobiologie.uni-halle.de

Strain $\mathrm{ZF2}^{\top}$, isolated from freshwater sediment, is a motile, rod-shaped, Grampositive, endospore-forming, amino acid- and pyruvate-utilizing, anaerobic bacterium. It requires yeast extract for growth. Carbohydrates are not utilized. The optimal temperature and $\mathrm{pH}$ for growth are $37^{\circ} \mathrm{C}$ and 6.8-7.3, respectively. The $\mathrm{G}+\mathrm{C}$ content of the DNA is $34.0 \mathrm{~mol} \%$. A 16S rDNA sequence analysis of strain $\mathrm{ZF2}^{\top}$ revealed that the highest similarity (94.4\%) was shared with Clostridium hydroxybenzoicum JW/Z-1 ${ }^{\top}$. Strain $\mathrm{ZF2}^{\top}$, however, was not able to carboxylate phenol or to decarboxylate 4-hydroxybenzoate, which are characteristic properties of strain JW/Z-1'. The degree of $16 \mathrm{~S}$ rDNA relatedness, together with the physiological and chemotaxonomic properties, suggest that strain $\mathrm{ZF2}^{\mathrm{T}}$ represents a novel species that is clearly distinct from Clostridium hydroxybenzoicum JW/Z-1 ${ }^{\top}$. In a phylogenetic dendrogram, both strains form a separate cluster that is peripherally associated with the Peptostreptococcus group (cluster XIII) of the clostridia and the lineage of Helcococcus kunzii. Strains $\mathrm{ZF2}^{\top}$ and JW/Z-1 ${ }^{\top}$ show a somewhat deeper branching from the cluster XII clostridia Clostridium purinolyticum and Clostridium acidiurici. The latter strains possessed the closest 165 rDNA similarity (between 88.4 and $90.7 \%$ ), but were clearly separated by phenotypic markers. Therefore, a new genus, Sedimentibacter gen. nov., is described, comprising Sedimentibacter hydroxybenzoicus gen. nov., comb. nov., as the type species of the genus, with

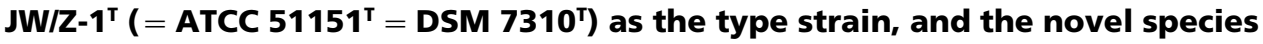
Sedimentibacter saalensis sp. nov., with strain ZF2 ${ }^{\top}$ ( = DSM $13558^{\top}=$ ATCC BAA$283^{\top}$ ) as the type strain.

Keywords: anaerobic low-G + C Gram-positive bacteria, Firmicutes, Clostridium hydroxybenzoicum, 16S rDNA, Sedimentibacter

\section{INTRODUCTION}

Clostridium hydroxybenzoicum $\mathrm{JW} / \mathrm{Z}-1^{\mathrm{T}}$ was isolated from a freshwater pond sediment during the investi-

Published online ahead of print on 14 December 2001 as DOI 10.1099/ ijs.0.01998-0.

Abbreviations: 3,4-OHB, 3,4-dihydroxybenzoate; 4-OHB, 4-hydroxybenzoate.

The GenBank/EMBL/DDBJ accession number for the $16 \mathrm{~S}$ rRNA sequence of Sedimentibacter saalensis strain $\mathrm{ZF}^{\top}{ }^{\top}$ is AJ404680. gation of anaerobic mineralization of 2,4-dichlorophenol, which was dechlorinated to phenol and further degraded, via carboxylation, to hydroxybenzoate (Zhang \& Wiegel, 1990b, 1992; Zhang et al., 1994). The reversible carboxylation/decarboxylation reaction was assigned to organisms similar, or identical, to strain JW/Z-1 ${ }^{\mathrm{T}}$. The biochemistry of this reaction has been studied in detail (Zhang \& Wiegel, 1994; He \& Wiegel, 1995, 1996). From its morphological, chemotaxonomic and physiological properties, this strain was assigned to the clostridia. However, analyses of 
the 16S rDNA of species of Clostridium and other related genera have revealed that the genus Clostridium is polyphyletic (Collins et al., 1994), and several species have been reclassified within newly created genera. In the case of strain $\mathrm{JW} / \mathrm{Z}-1^{\mathrm{T}}$, the $16 \mathrm{~S}$ rRNA gene sequence forms a separate line of descent that is only peripherally associated with cluster XIII and diverges from cluster XII of the clostridia (Zhang et al., 1994; Collins et al., 1994).

A novel isolate, $\mathrm{ZF}^{\mathrm{T}}$, was obtained from sediment of the Saale River in Germany by isolation from an anaerobic, 2,4,6-trichlorophenol-dehalogenating enrichment culture (Breitenstein et al., 2001) by using an agar-shake dilution series. This strain lacked both dehalogenating and carboxylation/decarboxylation activities, but $16 \mathrm{~S}$ rDNA sequence analysis revealed a high level of relatedness to strain JW/Z- $1^{\mathrm{T}}$. On the basis of phylogenetic and phenotypic properties, we propose the reclassification of $C$. hydroxybenzoicum to Sedimentibacter hydroxybenzoicus gen. nov., comb. nov., as the type species of Sedimentibacter gen. nov., strain $\mathrm{JW} / \mathrm{Z}-1^{\mathrm{T}}$ being the type strain. The newly isolated strain $\mathrm{ZF}^{\mathrm{T}}$ is described as a novel species in this genus, under the designation Sedimentibacter saalensis $\mathrm{sp}$. nov.

\section{METHODS}

Organisms, media and culture conditions. Strain $\mathrm{ZF} 2^{\mathrm{T}}$ was isolated from a $10^{-5}$ dilution step in an agar-shake dilution series of an anaerobic, dehalogenating, mixed culture enriched from sediment of the River Saale (Germany) by using $25 \mathrm{mM}$ pyruvate and $100 \mu \mathrm{M}$ 2,4,6-trichlorophenol as substrates (Breitenstein et al., 2001). A pure culture was obtained through three consecutive serial dilutions in agar shakes containing $25 \mathrm{mM}$ pyruvate and $0 \cdot 1 \%$ yeast extract. C. hydroxybenzoicum strain $\mathrm{JW} / \mathrm{Z}-1^{\mathrm{T}}\left(=\mathrm{DSM} 7310^{\mathrm{T}}\right)$ was obtained from the DSMZ. If not mentioned otherwise in the text, both strains were normally grown in minimal medium DC consisting of medium 1 (Holliger et al., 1992) containing $\left(1^{-1}\right) 10 \mathrm{mM}$ phosphate, trace elements according to Holliger et al. (1993), $16 \mathrm{nM} \mathrm{Na} \mathrm{SeO}_{3}, 12 \mathrm{nM} \mathrm{Na}{ }_{2} \mathrm{WoO}_{4}, 63 \mathrm{nM} 1,4-$ naphthoquinone and $5 \mathrm{~g}$ yeast extract, supplemented with $10 \mathrm{mM}$ L-arginine and $10 \mathrm{mM}$ glycine or $25 \mathrm{mM}$ pyruvate. The cultivation of the strains was carried out in volumes of $50-80 \mathrm{ml}$ in $125 \mathrm{ml}$ serum bottles or in $10 \mathrm{ml}$ aliquots in Hungate tubes under a $\mathrm{N}_{2} / \mathrm{CO}_{2}(4: 1)$ atmosphere at $30^{\circ} \mathrm{C}$ in the dark. Endospore formation was studied on Brewer's anaerobic agar. To test heat resistance, cells were rinsed off the agar with minimal medium, incubated in Hungate tubes for $30 \mathrm{~min}$ submerged in an $80^{\circ} \mathrm{C}$ water bath and then tested for growth with glycine and arginine. All experiments were performed in triplicate, unless otherwise indicated.

Growth parameters. The temperature range for growth was determined, using medium DC supplemented with $25 \mathrm{mM}$ pyruvate, to be between 4 and $40^{\circ} \mathrm{C}$. The $\mathrm{pH}$ range for growth was studied in medium DC containing glycine and Larginine and was adjusted to $\mathrm{pH}$ values in the range 5.5-9.0 with $50 \mathrm{mM}$ MES, phosphate or pyrophosphate buffer and suitable volumes of $1 \mathrm{M} \mathrm{HCl}$ or $1 \mathrm{M} \mathrm{KOH}$ prior to autoclaving under a $\mathrm{N}_{2}$ atmosphere. Growth was monitored by measuring the increase in optical density at $600 \mathrm{~nm}$.

Physiological characterization. Acid formation from carbohydrates, aesculin hydrolysis, indole production and gela- tinase and urease activities were tested for by using API 20A strips (bioMérieux). Cells were pre-grown in minimal medium with $0 \cdot 3 \%(\mathrm{w} / \mathrm{v})$ yeast extract and glycine and $\mathrm{L}-$ arginine, harvested by centrifugation and then washed twice with $10 \mathrm{mM}$ anaerobic phosphate buffer before inoculation of the API strips; the strips were incubated anaerobically at $30{ }^{\circ} \mathrm{C}$ and monitored after 24 and $48 \mathrm{~h}$. Sulfide production, indole formation and motility were tested for by using sulfide indole motility (SIM) medium according to Holdeman et al. (1977). Nitrate reduction was analysed using medium containing $0.5 \%$ yeast extract and supplemented with $25 \mathrm{mM}$ pyruvate and $0 \cdot 1 \% \mathrm{KNO}_{3}$ and commercially supplied test strips for the semi-quantitative detection of nitrate and nitrite.

Fermentation products. Volatile and non-volatile fatty acids were analysed by GC with Shimadzu-GC 14A equipment incorporating an FFAP capillary column $(25 \mathrm{~m} \times 0.25 \mathrm{~mm}$ internal diameter, $0.25 \mu \mathrm{m}$ film thickness) and a flameionization detector. Helium served as the carrier gas. The injector and detector were heated to 240 and $270{ }^{\circ} \mathrm{C}$, respectively. The volatile (i) and non-volatile fatty acids (ii) were analysed using the following temperature programmes: (i) initial column temperature $100^{\circ} \mathrm{C}$ for $3 \mathrm{~min}$, increased at a rate of $3{ }^{\circ} \mathrm{C} \mathrm{min}-1$ to $136{ }^{\circ} \mathrm{C}$ and at a rate of $40{ }^{\circ} \mathrm{C} \mathrm{min}{ }^{-1}$ to $220^{\circ} \mathrm{C}$; (ii) initial temperature $100^{\circ} \mathrm{C}$ for $6 \mathrm{~min}$, increased at a rate of $3{ }^{\circ} \mathrm{C} \mathrm{min}{ }^{-1}$ to $115^{\circ} \mathrm{C}$ and at a rate of $40{ }^{\circ} \mathrm{C} \mathrm{min}{ }^{-1}$ to $220^{\circ} \mathrm{C}$. Culture supernatants were pre-treated according to Nanninga \& Gottschal (1985) before direct measurement. Hydrogen was measured in the headspaces of Hungate tubes containing medium DC with $0.5 \%$ yeast extract and $25 \mathrm{mM}$ pyruvate. Incubation was for 8 days at $30{ }^{\circ} \mathrm{C}$ using a Reduction Gas Analyzer RGA2 (Traceanalytical) with $\mathrm{N}_{2}$ as the carrier gas, a 60/80 Molsieve 5A column and the following settings: oven and detector temperatures, 105 and

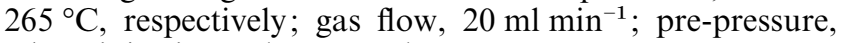
4 bar; injection volume, $1 \mathrm{ml}$.

Chemotaxonomic analyses. Lipid fatty acids and isoprenoid quinones were analysed as described by Lechner et al. (1995). Cell walls were prepared and the peptidoglycan structure determined by using the methods described by Schleifer \& Kandler (1972). Amino acids and peptides were separated and characterized by TLC on cellulose sheets.

Determination of DNA base composition. DNA was isolated and purified from $500 \mathrm{mg}$ freeze-dried cell material as described by Väisänen \& Salkinoja-Salonen (1989) with the modification that DNA extraction was carried out repeatedly with chloroform/isoamyl alcohol $(24: 1, \mathrm{v} / \mathrm{v})$ in the presence of $1 \mathrm{M} \mathrm{NaClO}_{4}$. The $\mathrm{G}+\mathrm{C}$ content (mol\%) was determined by HPLC of purified DNA digested to the nucleoside level according to the method of Tamaoka \& Komagata (1984).

Microscopic examinations. Cell morphology and motility were investigated by phase-contrast microscopy and transmission electron microscopy using cells from the exponential growth phase $(12 \mathrm{~h})$ and the stationary phase $(20 \mathrm{~h}, 48 \mathrm{~h}$ and 2 weeks old) grown in medium DC with either pyruvate or glycine and arginine as the carbon and energy source. Cells were negatively stained with $2 \%(\mathrm{w} / \mathrm{v})$ tungstophosphoric acid for electron microscopy. Gram-staining was performed according to standard methods (Gerhardt, 1981) with Escherichia coli K-12 (DSM 498) and Bacillus subtilis (DSM $347)$ as the respective controls.

Carboxylation and decarboxylation assay. The carboxylation of phenol and catechol was analysed using cell suspensions prepared as described by Zhang \& Wiegel (1994) from cells 
pre-grown in mineral medium containing $10 \mathrm{mM}$ L-arginine and $10 \mathrm{mM}$ glycine plus $6 \mathrm{mM}$ 4-hydroxybenzoate (4-OHB) or $4 \mathrm{mM} 3$,4-dihydroxybenzoate (3,4-OHB), respectively, as potential inducers of the reversible decarboxylases (Zhang \& Wiegel, 1990a). The decarboxylation of 4-OHB and 3,4$\mathrm{OHB}$ was tested for using supernatants of cultures grown in mineral medium supplemented with $10 \mathrm{mM}$ L-arginine and $10 \mathrm{mM}$ glycine plus $1.5 \mathrm{mM} 4-\mathrm{OHB}$ or $1.5 \mathrm{mM} 3,4-\mathrm{OHB}$, respectively. Measurement of the carboxylation of phenol and the decarboxylation of 4-OHB was performed by HPLC on a LiChrospher 100 -RP 18 column $(250 \times 4 \mathrm{~mm}, 10 \mu \mathrm{m}$, $100 \AA)$ at $35^{\circ} \mathrm{C}$ using a mobile phase of methanol/water $(1$ : 1 ), acidified to $\mathrm{pH} 3$ with acetic acid, at a constant flow rate of $1 \mathrm{ml} \mathrm{min}$. The wavelength used for detection was $260 \mathrm{~nm}$. The carboxylation/decarboxylation of catechol/ 3,4-OHB was analysed using a mobile phase of methanol/ water $(5: 95)$ at a constant flow rate of $0.9 \mathrm{ml} \mathrm{min}^{-1}$ and a detection wavelength of $275 \mathrm{~nm}$. Cells of strain $\mathrm{JW} / \mathrm{Z}-1^{\mathrm{T}}$ were used as positive controls for the carboxylation and decarboxylation reactions.

Determination and analysis of 16S rRNA gene sequence. The 16S rRNA gene was PCR-amplified using the universal eubacterial primers fD1 and rP2 (Weisburg et al., 1991) from $1 \mu \mathrm{l}$ of a suspension of one colony in $50 \mu \mathrm{l}$ water and subjected to five freeze/thaw cycles. Purification, cloning and bidirectional sequencing of the amplified PCR product were performed as described previously (Breitenstein et al., 2001). The sequence was used for similarity searches against the EMBL and GenBank databases, using the FASTA 3 program (Pearson, 1990). Multiple sequence alignments were performed using the CLUSTAL W program, version 1.7 (Thompson et al., 1994). Positions containing unidentified nucleotides were excluded from the alignment, which was subsequently based on 1305 nt (28-1400 bp, E. coli numbering). The phylogenetic analyses were performed with the PHYLIP 3.5c program package (Felsenstein, 1993). Evolutionary distances were calculated with the DNADIST program according to the algorithm of Jukes \& Cantor (1969). The unrooted phylogenetic tree was constructed using the neighbour-joining method and the Jukes-Cantor correction (Jukes \& Cantor, 1969). Bootstrapping was performed with the programs SEQBOOT, DNADIST and CONSENSE.

\section{RESULTS AND DISCUSSION}

\section{Cell morphology}

Cells of strain $\mathrm{ZF}^{\mathrm{T}}$ were rod-shaped $(0 \cdot 5-0 \cdot 7 \mu \mathrm{m}$ wide ; $3 \cdot 7-6 \cdot 0 \mu \mathrm{m}$ long), occurring singly or in chains of two cells up to 12 or more cells. In addition, long filaments of up to $130 \mu \mathrm{m}$ appeared (Fig. 1a), sometimes having only a few, or no, visible septations. However, staining with 4',6-diamidino-2-phenylindole (DAPI; $0.05 \mu \mathrm{g} \mathrm{ml}^{-1}$ ) indicated the presence of approximately one nucleoid every $4-6 \mu \mathrm{m}$. Cells were motile by three to four peritrichously inserted flagella (Fig. 1b). Pili up to $1 \mu \mathrm{m}$ in length and $5 \mathrm{~nm}$ thick were present only on some of the cells (not shown). Motility could be demonstrated in SIM medium and under the light microscope when a freshly withdrawn sample was studied immediately. No flagella were described for strain JW $/ Z-1^{\mathrm{T}}$ (Zhang et al., 1994). However, under the conditions described here for $\mathrm{ZF}^{\mathrm{T}}$, flagella were also found on some cells in preparations of strain

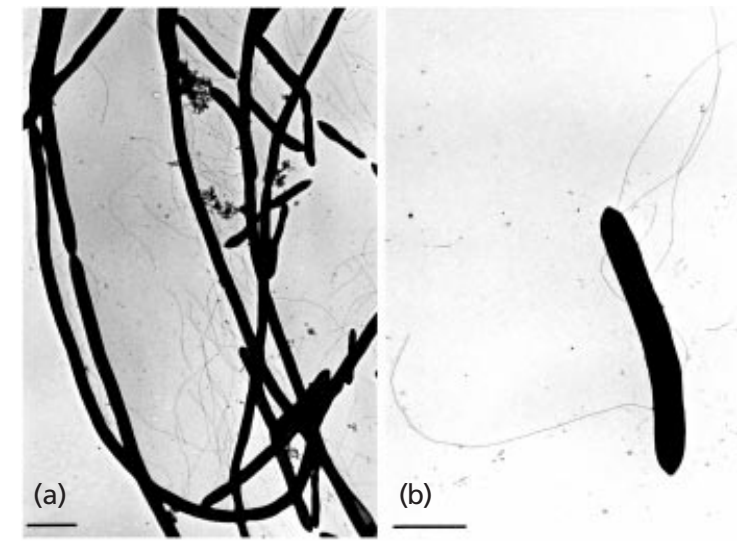

Fig. 1. Transmission electron micrographs of strain $Z F 2^{\top}$, showing long filaments (a) and a single flagellated cell (b) present in a 20-h culture. Bars, 2.5 (a) and 1 (b) $\mu \mathrm{m}$.

$\mathrm{JW} / \mathrm{Z}-1^{\mathrm{T}}$. Gram-staining of $\mathrm{ZF} 2^{\mathrm{T}}$ resulted in a faint blue colour that was regarded as positive in comparison with the reference strains. Heat-resistant $\left(80^{\circ} \mathrm{C}, 30 \mathrm{~min}\right)$, oval endospores were formed on Brewer's anaerobic agar.

\section{Biochemical and physiological characteristics}

Growth requirements, temperature and $\mathrm{pH}$ range. Strain $\mathrm{ZF} 2^{\mathrm{T}}$ is an obligately anaerobic, chemo-organotrophic bacterium. The optimal growth temperature was $37^{\circ} \mathrm{C}$, and growth was observed between 14 and $40{ }^{\circ} \mathrm{C}$; no growth was observed at 4 or $45^{\circ} \mathrm{C}$. The $\mathrm{pH}$ range for growth was $5 \cdot 8-8 \cdot 0$, the optimum being between $\mathrm{pH} 6.8$ and $7 \cdot 3$. No growth occurred at $\mathrm{pH} 5.5$ or 8.5 . Strain $\mathrm{ZF} 2^{\mathrm{T}}$ required at least $0.01 \%$ yeast extract for growth. The maximum growth yield was obtained when $0 \cdot 3-0 \cdot 5 \%$ yeast extract was added to medium DC containing $25 \mathrm{mM}$ pyruvate.

Substrate utilization and acid production. The amino acids L-arginine, glycine and L-lysine had different effects on the growth of strain $\mathrm{ZF} 2^{\mathrm{T}}$ when added singly or in combination to medium containing $0.5 \%(\mathrm{w} / \mathrm{v})$ yeast extract (Table 1). Glycine and L-lysine supported growth as single substrates and were fermented to almost equimolar amounts of acetate and acetate plus butyrate, respectively. The amino acid fermentation of strain $\mathrm{ZF} 2^{\mathrm{T}}$ resembled that of $C$. hydroxybenzoicum strain JW/Z-1 ${ }^{\mathrm{T}}$ (Zhang et al., 1994) except for the Llysine fermentation. Strain $\mathrm{ZF} 2^{\mathrm{T}}$ produced both acetate and butyrate from L-lysine, whereas strain $\mathrm{JW} / \mathrm{Z}$ $1^{\mathrm{T}}$ largely produced butyrate (Zhang et al., 1994). However, the increased acetate production from lysine plus glycine at the expense of butyrate indicated that glycine functioned as the electron acceptor for both strains. The addition of arginine to glycine led to an increase in growth and acetate formation, suggesting a Stickland-type reaction with glycine reduction and arginine oxidation to acetate (Seto, 1980; Andreesen et al., 1989). However, the addition of arginine alone did 
Table 1. Growth and volatile fatty acid production by strain $\mathrm{ZF}^{\top}$ in minimal medium with and without the addition of certain amino acids

All amino acids were added at $10 \mathrm{mM}$. A value for growth of $100 \%$ was equivalent to an $\mathrm{OD}_{600}$ of $0 \cdot 28$. The medium contained $0.5 \%$ yeast extract. The concentrations of fatty acids determined were corrected for the amounts of fatty acids present in the yeast extract at time zero.

\begin{tabular}{|lcrcccc|}
\hline Addition(s) & $\begin{array}{c}\text { Growth } \\
(\%)\end{array}$ & \multicolumn{5}{c|}{ Concentration of volatile fatty acid produced (mM) } \\
\cline { 3 - 7 } & & Acetate & Propionate & Isobutyrate & Butyrate & Isovalerate \\
\hline None & 100 & $3 \cdot 3$ & $0 \cdot 45$ & 0 & $1 \cdot 2$ & $0 \cdot 11$ \\
Arg & 71 & $3 \cdot 2$ & $0 \cdot 33$ & 0 & 0 & 0 \\
Gly & 179 & $14 \cdot 1$ & $0 \cdot 94$ & $0 \cdot 14$ & 0 & $0 \cdot 70$ \\
Lys & 257 & $11 \cdot 0$ & $0 \cdot 60$ & 0 & $11 \cdot 3$ & $0 \cdot 34$ \\
Arg + Gly & 261 & $20 \cdot 0$ & $0 \cdot 62$ & $0 \cdot 10$ & $1 \cdot 9$ & $0 \cdot 56$ \\
Gly + Lys & 261 & $27 \cdot 0$ & $1 \cdot 30$ & $0 \cdot 42$ & $7 \cdot 8$ & $0 \cdot 80$ \\
\hline
\end{tabular}

Table 2. Growth and production of volatile and non-volatile fatty acids in minimal medium containing $0.5 \%$ yeast extract

The initial $\mathrm{OD}_{600}$ was $0 \cdot 1$. Values are means of three replicate cultures in early stationary phase (after $19 \cdot 5 \mathrm{~h}$ for strain $\mathrm{ZF} 2^{\mathrm{T}}$ and $27 \cdot 5 \mathrm{~h}$ for strain $\mathrm{JW} / \mathrm{Z}-1^{\mathrm{T}}$ ). Values were corrected for the amounts of fatty acids present in the yeast extract at time zero.

\begin{tabular}{|c|c|c|c|c|c|c|c|c|}
\hline \multirow[t]{2}{*}{ Strain } & \multirow[t]{2}{*}{ Substrate } & \multirow{2}{*}{$\begin{array}{l}\text { Growth } \\
\left(O_{600}\right)\end{array}$} & \multicolumn{6}{|c|}{ Concentration of fatty acid produced (mM) } \\
\hline & & & Acetate & Butyrate & Lactate & Propionate & Isobutyrate & Isovalerate \\
\hline \multirow[t]{2}{*}{$\mathrm{ZF} 2^{\mathrm{T}}$} & Pyruvate $(25 \mathrm{mM})$ & $0 \cdot 88$ & $11 \cdot 7$ & $5 \cdot 0$ & $0 \cdot 5$ & $0 \cdot 5$ & $0 \cdot 1$ & $0 \cdot 07$ \\
\hline & None & $0 \cdot 45$ & $1 \cdot 8$ & 1.9 & 0 & $0 \cdot 4$ & 0 & $0 \cdot 05$ \\
\hline \multirow[t]{2}{*}{$\mathrm{JW} / \mathrm{Z}-1^{\mathrm{T}}$} & Pyruvate $(25 \mathrm{mM})$ & $0 \cdot 54$ & $12 \cdot 0$ & $0 \cdot 9$ & $0 \cdot 2$ & $0 \cdot 5$ & $0 \cdot 6$ & $1 \cdot 00$ \\
\hline & None & $0 \cdot 20$ & $2 \cdot 0$ & $1 \cdot 4$ & $0 \cdot 2$ & $0 \cdot 3$ & $0 \cdot 3$ & $0 \cdot 50$ \\
\hline
\end{tabular}

not support growth. This was also described for strain $\mathrm{JW} / \mathrm{Z}-1^{\mathrm{T}}$ (Zhang et al., 1994) and is in contrast to the situation for many clostridia, which can use the energyproviding arginine deiminase pathway (Andreesen $e t$ $a l$., 1989). Strain $\mathrm{JW} / \mathrm{Z}-1^{\mathrm{T}}$ converted arginine to ornithine (Zhang et al., 1994), perhaps because of an arginase reaction (Cunin et al., 1986). In the presence of glycine, ornithine was converted to alanine (Zhang et al., 1994), suggesting that ornithine might function as the electron donor, as it does in many amino-acidutilizing clostridia (Andreesen et al., 1989).

The growth of strains $\mathrm{ZF} 2^{\mathrm{T}}$ and $\mathrm{JW} / \mathrm{Z}-1^{\mathrm{T}}$ on $25 \mathrm{mM}$ pyruvate was compared (Table 2 ). In the case of $\mathrm{ZF}^{\mathrm{T}}$, the optical density increased twofold relative to that for growth on minimal medium containing $0.5 \%$ yeast extract but no pyruvate. Strain JW $/ Z-1^{\mathrm{T}}$ was described as not growing with pyruvate as the substrate (Zhang et al., 1994). However, under the conditions applied here, pyruvate fermentation was also observed for strain JW/Z-1 ${ }^{\mathrm{T}}$, although with a lower growth yield compared with strain $\mathrm{ZF}^{\mathrm{T}}$. The main fermentation products of strain $\mathrm{ZF}^{\mathrm{T}}$ were acetate and butyrate, suggesting that pyruvate was oxidized to acetate, which, in part, might have served as an electron acceptor in the formation of butyrate. Strain JW/Z-1 ${ }^{\mathrm{T}}$ formed almost the same amount of acetate but smaller amounts of butyrate and larger amounts of isobutyrate and isovalerate (Table 2). The latter branched-chain fatty acids were probably formed from the respective amino acids present in the yeast extract (Andreesen et al., 1989). Electrons produced during oxidative metabolism were probably transferred to acetate to form butyrate, as has been described for Clostridium acetireducens (Girbal et al., 1997). This is supported by the fact that neither strain produced hydrogen under these conditions.

Strain $\mathrm{ZF} 2^{\mathrm{T}}$ did not produce acids from glucose, mannitol, lactose, sucrose, maltose, salicin, xylose, arabinose, glycerol, cellobiose, mannose, melezitose, raffinose, sorbitol, rhamnose or trehalose in the API $20 \mathrm{~A}$ test system. Uric acid, hypoxanthine, xanthine, guanine and adenine (10 $\mathrm{mM}$ each) did not stimulate 
Table 3. Characteristics of strain $\mathrm{ZF} 2^{\top}$ compared with those of strain $\mathrm{JW} / \mathrm{Z}-1^{\top}$

+ , Positive; - , negative. Cells of both strains were slightly curved, motile rods. The following characteristics tested positive for both strains: fermentation of pyruvate, glycine and lysine and of arginine plus glycine; formation of $\mathrm{H}_{2} \mathrm{~S}$ in SIM medium. Both contained the peptidoglycan type A $1 \alpha$, LLys-direct and the cellular fatty acids 14:0, 16:0, 18:0, 16:1 cis-9 and 18:1 cis-11 and the dimethyl acetals 16:0 and 18:0. The following characteristics tested negative for both strains: catalase, gelatin hydrolysis, nitrate reduction, fermentation of carbohydrates and purines and production of $\mathrm{H}_{2}$.

\begin{tabular}{|lll|}
\hline Characteristic & Strain $\mathbf{Z F 2}^{\mathrm{T}}$ & Strain $\mathbf{J W} / \mathbf{Z}^{\mathbf{T}}{ }^{\mathrm{T} *}$ \\
\hline Cell size $(\mu \mathrm{m})$ & $0 \cdot 5-0 \cdot 7$ & $0 \cdot 35-0 \cdot 67$ \\
& $\times 3 \cdot 7-6 \cdot 0$ & $\times 2 \cdot 5-5 \cdot 1$ \\
Spore shape & Oval & Round \\
Gram-stain reaction & + & - \\
G + C content $(\mathrm{mol} \%)$ & $34 \cdot 0$ & $35 \cdot 5$ \\
Optimum temp. $\left({ }^{\circ} \mathrm{C}\right)$ & 37 & $33-34$ \\
Optimum pH & $6 \cdot 8-7 \cdot 3$ & $7 \cdot 2-8 \cdot 2$ \\
Indole production & - & + \\
Decarboxylation of: & & \\
4-OHB & - & + \\
3,4-OHB & - & + \\
\hline
\end{tabular}

* Data were taken partly from Zhang et al. (1994).

growth of strain $\mathrm{ZF}^{\mathrm{T}}$ when added to the minimal medium in which selenite was present. This is in accordance with the data reported for $\mathrm{JW} / \mathrm{Z}-1^{\mathrm{T}}$ (Zhang et al., 1994).

Biochemical properties. Strain $\mathrm{ZF} 2^{\mathrm{T}}$ did not hydrolyse aesculin or gelatin. No indole was produced from tryptophan and catalase and urease were absent. Nitrate was not reduced. Strain $Z F 2^{\mathrm{T}}$ produced $\mathrm{H}_{2} \mathrm{~S}$ from thiosulfate when grown in SIM medium (Holdeman et al., 1977).

Carboxylation and decarboxylation ability. C. hydroxybenzoicum $\mathrm{JW} / \mathrm{Z}-1^{\mathrm{T}}$ has been described as reversibly decarboxylating 3,4-OHB to catechol and 4-OHB to phenol (Zhang \& Wiegel, 1990a, 1994). Carboxylation/decarboxylation was studied with the two strains in parallel. Cell suspensions of JW/Z-1 ${ }^{\mathrm{T}}$ formed carboxylated products from phenol or catechol in the $0.1 \mathrm{mM}$ range, as described by Zhang \& Wiegel (1994), and converted $2 \mathrm{mM} 4-\mathrm{OHB}$ and $1 \mathrm{mM} \mathrm{3,4-}$ OHB completely to phenol and catechol within 50 and $85 \mathrm{~h}$, respectively. However, strain $\mathrm{ZF} 2^{\mathrm{T}}$ neither carboxylated phenol or catechol nor decarboxylated $3,4-\mathrm{OHB}$ or 4-OHB (under identical conditions).

Chemotaxonomic data. Purified cell walls of strain $\mathrm{ZF}^{\mathrm{T}}$ contained muramic acid, glucosamine and the amino acids lysine, glutamate and alanine in the molar ratio $1: 1: 2$. The fingerprints of chromatograms of the partial hydrolysate were consistent with the peptido- glycan type A1 $\alpha$, L-Lys-direct. The lipid fatty acid composition of cells grown with $40 \mathrm{mM}$ pyruvate was as follows: fatty acids, $12: 0(1 \cdot 4 \%), 14: 0(13 \cdot 2 \%), 16$ : 1 cis-7 (4.4\%), 16:1 cis-9 (10.9\%), 16:0 (11.8\%), 18 : 1 cis-9 $(7 \cdot 7 \%)$ and 18:0 (6.8\%); aldehydes, 16:0 $(1.0 \%)$ and 18:0 (1.0\%); dimethyl acetals, 16:1 cis-9 $(2 \cdot 1 \%), 16: 0(5 \cdot 0 \%), 18: 1$ cis-9 $(5 \cdot 5 \%), 18: 1$ cis-11 $(3.9 \%)$ and 18:0 (6.5\%). All other components were below $1 \%$. The lipid fatty acid composition of $C$. hydroxybenzoicum $\mathrm{JW} / \mathrm{Z}-\mathrm{1}^{\mathrm{T}}$ was investigated under identical conditions and was shown to possess the same spectrum of fatty acids, albeit in slightly different proportions (data not shown), e.g. fatty acids 14:0 $(27 \cdot 7 \%)$ and $16: 0(13 \cdot 1 \%)$, and dimethyl acetals 16:0 $(11.2 \%)$ were significantly increased at the expense of the unsaturated fatty acids $16: 1$ and $18: 1$, which were present in smaller proportions. Cluster analysis of the cellular fatty acids of both strains using MIDI software (Microbial ID) revealed 22.3 Euclidian distances, suggesting that the two strains belong to two different species within a genus. Quinones were not detected in strain $\mathrm{ZF}^{\mathrm{T}}$. The $\mathrm{G}+\mathrm{C}$ content of the DNA of strain $\mathrm{ZF}^{\mathrm{T}}$ (34.0 $\mathrm{mol} \%$ ) was slightly lower than that obtained for strain $\mathrm{JW} / \mathrm{Z}-1^{\mathrm{T}}(35.5 \mathrm{~mol} \%$ ) (Zhang et al., 1994); both values were determined by HPLC measurement and are well within the range required for members of the same genus.

The characteristics determined for strain $\mathrm{ZF}^{\mathrm{T}}$ are summarized in Table 3 and compared with those of strain $\mathrm{JW} / \mathrm{Z}-1^{\mathrm{T}}$.

\section{Phylogeny of strain $\mathrm{ZF2}^{\top}$}

The almost complete 16S rRNA gene sequence (1434 nt, 28-1492 bp, E. coli numbering; Brosius et al., 1978) of strain $\mathrm{ZF} 2^{\mathrm{T}}$ was determined. Comparative sequence searches of the EMBL and GenBank databases revealed that the $16 \mathrm{~S}$ rDNA sequence was related to those of the Clostridium subphylum of the Grampositive bacteria (Fig. 2). Within this subphylum, the highest sequence identity, $94 \cdot 4 \%$, was obtained with the $16 \mathrm{~S}$ rRNA sequence of $C$. hydroxybenzoicum $\mathrm{JW} / \mathrm{Z}-1^{\mathrm{T}}$ (Zhang et al., 1994), whereas values for similarity to other members of the clostridial subphylum were much lower (below $91 \%$ ). The sequences of strains $\mathrm{ZF} 2^{\mathrm{T}}$ and $\mathrm{JW} / \mathrm{Z}-1^{\mathrm{T}}$ form a common cluster, clearly separated from the Peptostreptococcus branch of clostridial cluster XIII and from the cluster XII organisms Clostridium purinolyticum and Clostridium acidiurici (Collins et al., 1994). The latter two organisms (possessing 16S rDNA similarities to strains $\mathrm{ZF} 2^{\mathrm{T}}$ and $\mathrm{JW} / \mathrm{Z}-1^{\mathrm{T}}$ of $88 \cdot 4-90 \cdot 7 \%$ ) are specialized for the degradation of purines (Andreesen et al., 1989), which were not attacked by strains $\mathrm{JW} / \mathrm{Z}-1^{\mathrm{T}}$ (Zhang et al., 1994) and ZF2 ${ }^{\mathrm{T}}$.

Thus, strain $\mathrm{ZF} 2^{\mathrm{T}}$ is described as a novel species, Sedimentibacter saalensis sp. nov., within the novel genus Sedimentibacter, Sedimentibacter hydroxybenzoicus gen. nov., comb. nov., being the type species. 


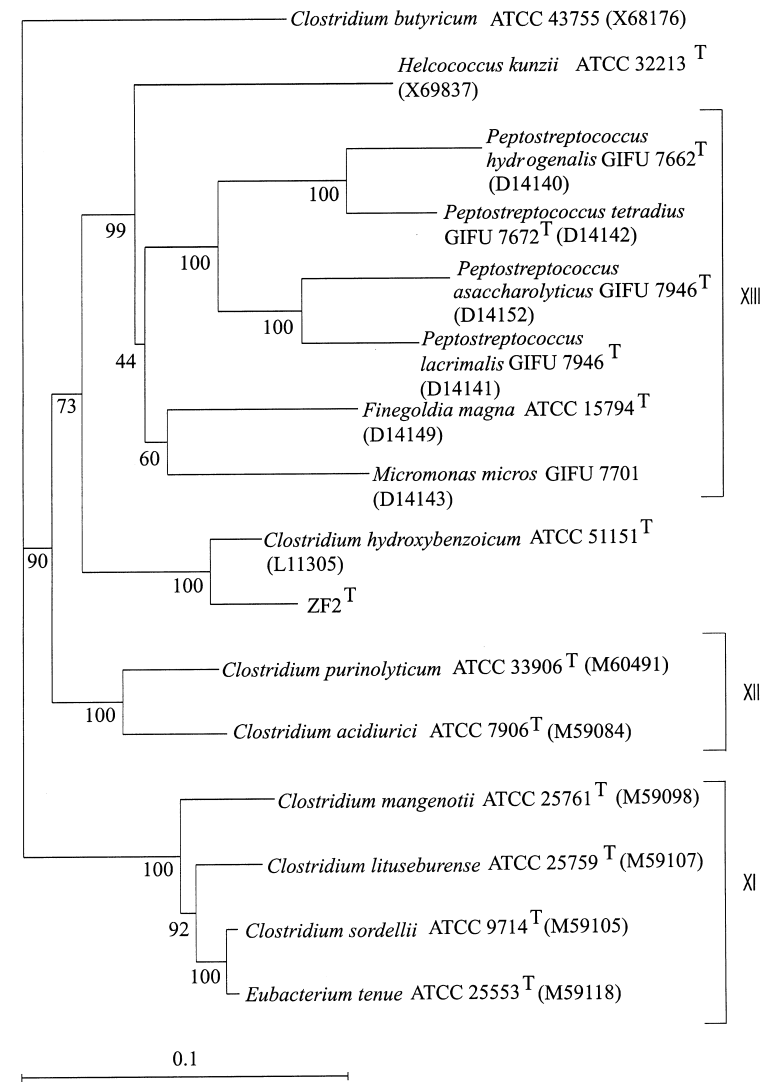

Fig. 2. Phylogenetic tree indicating the position of strain $Z F 2^{\top}$ as a close relative of Clostridium hydroxybenzoicum JW/Z-1 $1^{\top}$ within the radiation of selected representatives of the lowG + C, Gram-positive bacteria. Clostridium butyricum (cluster I) was used as an outgroup. Percentage bootstrap values are based on 500 replicates and are indicated at the branching points. Accession numbers are given in parentheses. Roman numerals indicate the corresponding clostridial clusters according to Collins et al. (1994). Bar, 0.1 nucleotide substitutions per site.

\section{Description of Sedimentibacter gen. nov.}

Sedimentibacter (Se.di.men.ti.bac'ter. N.L. masc. n. sedimentum sediment; N.L. n. bacter masc. equivalent of Gr. neut. n. bakterion rod or staff; N.L. masc. n. Sedimentibacter rod from sediment, referring to its origin).

Cells are slightly curved rods with peritrichously arranged flagella. Spores might be formed. The Gram type positive cell wall is of the A1 $\alpha$, L-Lys-direct peptidoglycan type. Growth is strictly anaerobic and requires yeast extract and is supported by the fermentation of pyruvate or of amino acids in a Sticklandtype reaction. $\mathrm{H}_{2}$ is not produced. Carbohydrates are not fermented. The purines uric acid, adenine, hypoxanthine, guanine and xanthine are not utilized. Catalase and urease are absent. Sedimentibacter represents a novel line of descent in the branch of low-G $+\mathrm{C}$, Gram-positive bacteria, according to $16 \mathrm{~S}$ rDNA sequence analysis. Members of the genus
Sedimentibacter can be distinguished from each other by their $16 \mathrm{~S}$ rDNA sequences. The type species is Sedimentibacter hydroxybenzoicus.

\section{Description of Sedimentibacter hydroxybenzoicus comb. nov.}

Basonym: Clostridium hydroxybenzoicum (Zhang et al. 1994).

Properties of strain $\mathrm{JW} / \mathrm{Z}-1^{\mathrm{T}}$ are as described previously (Zhang \& Wiegel, 1994), with the exception of the new information that flagellated cells can be observed occasionally and that pyruvate is fermented in yeast-extract-containing medium. The type strain is $\mathrm{JW} / \mathrm{Z}-1^{\mathrm{T}}\left(=\right.$ ATCC $\left.51151^{\mathrm{T}}=\mathrm{DSM} 7310^{\mathrm{T}}\right)$.

\section{Description of Sedimentibacter saalensis sp. nov.}

Sedimentibacter saalensis (saa.len'sis. N.L. adj. saalensis referring to the German River Saale, from which the organism was isolated).

Cells are strictly anaerobic, slightly curved rods that are $0.5-0.7 \mu \mathrm{m}$ in diameter and $3.7-6.0 \mu \mathrm{m}$ long, occurring singly, in pairs or in chains of up to 12 cells. In addition, long filaments with no visible septation occur. Motile by peritrichously arranged flagella. Gram-staining of different growth phases gives a positive result. The cell wall type is A $1 \alpha$, L-Lys-direct. Oval spores $(0.7 \mu \mathrm{m}$ diameter $)$ are formed on complex medium. The temperature range for growth is 14 $40{ }^{\circ} \mathrm{C}$, the optimum temperature being $37^{\circ} \mathrm{C}$. The $\mathrm{pH}$ range for growth is $5 \cdot 8-8 \cdot 0$; there is a broad optimum range of $\mathrm{pH} 6 \cdot 8-7 \cdot 3$. Requires yeast extract for growth. The addition of $25 \mathrm{mM}$ pyruvate, $10 \mathrm{mM}$ glycine or $10 \mathrm{mM}$ L-lysine, or of combinations of glycine plus arginine or glycine plus lysine, to yeast-extract-containing medium supports growth. The major fermentation products during growth on pyruvate are acetate and butyrate, whereas propionate, lactate and traces of isobutyrate and isovalerate are minor products (in a medium containing $0.5 \%$ yeast extract); $\mathrm{H}_{2}$ is not formed. No acid production from glucose, mannitol, lactose, sucrose, maltose, salicin, xylose, arabinose, glycerol, cellobiose, mannose, melezitose, raffinose, sorbitol, rhamnose or trehalose. Uric acid, adenine, hypoxanthine, guanine and xanthine are not utilized. Tests for catalase and urease activity, indole production, reduction of nitrate to nitrite, gelatin liquefaction and hydrolysis of aesculin are negative. Forms sulfide. The major fatty acids are 14:0, 16:1 cis-9 and $16: 0$. The genomic DNA G $+\mathrm{C}$ content is $34 \cdot 0 \mathrm{~mol} \%$. The type strain, ZF2 ${ }^{\mathrm{T}}\left(=\mathrm{DSM} 13558^{\mathrm{T}}=\mathrm{ATCC}\right.$ BAA $-283^{\mathrm{T}}$ ), was isolated from freshwater sediment of the River Saale (Germany).

\section{ACKNOWLEDGEMENTS}

This work was supported by the Graduiertenförderung of Sachsen-Anhalt, Germany, and the Fonds der Chemischen Industrie. The authors are grateful to Gerd Hause (Biozentrum Halle) for electron microscopy and Hendrik 
Ballerstedt (TNO Environment, Energy and Process Innovation, Apeldoorn, The Netherlands) for hydrogen measurement.

\section{REFERENCES}

Andreesen, J. R., Bahl, H. \& Gottschalk, G. (1989). Introduction to the physiology and biochemistry of the genus Clostridium. In Clostridia. Biotechnology Handbooks 3, pp. 27-62. Edited by N. P. Minton \& D. L. Clarke. New York: Plenum.

Breitenstein, A., Saano, A., Salkinoja-Salonen, M., Andreesen, J. R. \& Lechner, U. (2001). Analysis of a 2,4,6-trichlorophenoldehalogenating enrichment culture and isolation of the dehalogenating member Desulfitobacterium frappieri strain TCP-A. Arch Microbiol 175, 133-142.

Brosius, J., Palmer, M. L., Kennedy, P. J. \& Noller, H. F. (1978). Complete nucleotide sequence of a $16 \mathrm{~S}$ ribosomal RNA gene from Escherichia coli. Proc Natl Acad Sci U S A 75, 4801-4805.

Collins, M. D., Lawson, P. A., Willems, A., Cordoba, J. J., Fernandez-Garayzabal, J., Garcia, P., Cai, J., Hippe, H. \& Farrow, J. A. E. (1994). The phylogeny of the genus Clostridium: proposal of five new genera and eleven new species combinations. Int $J$ Syst Bacteriol 44, 812-826.

Cunin, R., Glansdorff, N., Pierard, A. \& Stalon, V. (1986). Biosynthesis and metabolism of arginine in bacteria. Microbiol Rev 50, 314-352.

Felsenstein, J. (1993). PHYLIP: phylogenetic inference package, version 3.5. Seattle: University of Washington.

Gerhardt, P. (1981). Manual of Methods for General Bacteriology. Washington, DC: American Society for Microbiology.

Girbal, L., Örlygsson, J., Reinders, B. J. \& Gottschal, J. C. (1997). Why does Clostridium acetireducens not use interspecies hydrogen transfer for growth on leucine? Curr Microbiol 35, 155-160.

He, Z. \& Wiegel, J. (1995). Purification and characterization of an oxygen-sensitive reversible 4-hydroxybenzoate decarboxylase from Clostridium hydroxybenzoicum. Eur J Biochem 229, 77-82.

He, Z. \& Wiegel, J. (1996). Purification and characterization of an oxygen-sensitive, reversible 3,4-dihydroxybenzoate decarboxylase from Clostridium hydroxybenzoicum. J Bacteriol 178, 3539-3543.

Holdeman, L. V., Cato, E. P. \& Moore, W. E. C. (1977). Anaerobe Laboratory Manual, 4th edn. Blacksburg, VA: Virginia Polytechnic Institute and State University Anaerobe Laboratory.

Holliger, C., Schraa, G., Stams, A. J. M. \& Zehnder, A. J. B. (1992). Enrichment and properties of an anaerobic mixed culture reductively dechlorinating 1,2,3-trichlorobenzene to 1,3-dichlorobenzene. Appl Environ Microbiol 58, 1636-1644.

Holliger, C., Schraa, G., Stams, A. J. M. \& Zehnder, A. J. B. (1993). A highly purified enrichment culture couples the reductive dechlorination of tetrachloroethene to growth. Appl Environ Microbiol 59, 2991-2997.

Jukes, T. H. \& Cantor, C. R. (1969). Evolution of protein molecules. In Mammalian Protein Metabolism, pp. 21-132. Edited by H. N. Munro. New York: Academic Press.

Lechner, U., Baumbach, R., Becker, D., Kitunen, V., Auling, G. \& Salkinoja-Salonen, M. (1995). Degradation of 4-chloro-2methylphenol by an activated sludge isolate and its taxonomic description. Biodegradation 6, 83-92.

Nanninga, H. J. \& Gottschal, J. C. (1985). Amino acid fermentation and hydrogen transfer in mixed cultures. FEMS Microbiol Ecol 31, 261-269.

Pearson, W. R. (1990). Rapid and sensitive sequence comparison with FASTP and FASTA. Methods Enzymol 183, 63-98.

Schleifer, K. H. \& Kandler, O. (1972). Peptidoglycan types of bacterial cell walls and their taxonomic implications. Bacteriol Rev 36, 407-477.

Seto, B. (1980). The Stickland reaction. In Diversity in Bacterial Respiratory Systems, pp. 49-64. Edited by C. J. Knowles. Boca Raton, FL: CRC Press.

Tamaoka, J. \& Komagata, K. (1984). Determination of DNA base composition by reversed-phase high-performance liquid chromatography. FEMS Microbiol Lett 25, 125-128.

Thompson, J. D., Higgins, D. G. \& Gibson, T. J. (1994). CLUSTAL W: improving the sensitivity of progressive multiple sequence alignment through sequence weighting, position-specific gap penalties and weight matrix choice. Nucleic Acids Res 22, 4673-4680.

Väisänen, O. \& Salkinoja-Salonen, M. (1989). Use of phage typing and fatty acid analysis for the identification of bacilli isolated from food packaging paper and board machines. Syst Appl Microbiol 12, 103-111.

Weisburg, W. G., Barns, S. M., Pelletier, D. A. \& Lane, D. J. (1991). $16 \mathrm{~S}$ ribosomal DNA amplification for phylogenetic study. $J$ Bacteriol 173, 697-703.

Zhang, X. \& Wiegel, J. (1990a). Isolation and partial characterization of a Clostridium sp. transforming p-hydroxybenzoate and 3,4dihydroxybenzoate and producing phenols as the final transformation products. Microb Ecol 20, 103-122.

Zhang, X. \& Wiegel, J. (1990b). Sequential anaerobic degradation of 2,4-dichlorophenol in freshwater sediments. Appl Environ Microbiol 56, $1119-1127$

Zhang, X. \& Wiegel, J. (1992). The anaerobic degradation of 3-chloro4-hydroxybenzoate in freshwater sediment proceeds via either chlorophenol or hydroxybenzoate to phenol and subsequently to benzoate. Appl Environ Microbiol 58, 3580-3585.

Zhang, X. \& Wiegel, J. (1994). Reversible conversion of 4hydroxybenzoate and phenol by Clostridium hydroxybenzoicum. Appl Environ Microbiol 60, 4182-4185.

Zhang, X., Mandelco, L. \& Wiegel, J. (1994). Clostridium hydroxybenzoicum sp. nov., an amino acid-utilizing, hydroxybenzoatedecarboxylating bacterium isolated from methanogenic freshwater pond sediment. Int J Syst Bacteriol 44, 214-222. 